\title{
Use of ultrasound guidance to improve the safety of percutaneous dilatational tracheostomy: a literature review
}

Mariam Alansari ${ }^{1 *}$, Hadil Alotair ${ }^{1}$, Zohair Al Aseri $^{2}$ and Mohammed A Elhoseny ${ }^{1}$

\begin{abstract}
Patients in ICUs frequently require tracheostomy for long-term ventilator support, and the percutaneous dilatational tracheostomy (PDT) method is preferred over surgical tracheostomy. The use of ultrasound (US) imaging to guide ICU procedures and interventions has recently emerged as a simple and noninvasive tool. The current evidence regarding the applications of US in PDT is encouraging; however, the exact role of US-guided dilatational tracheostomy (US-PDT) remains poorly defined. In this review, we describe the best available evidence concerning the safety and efficacy of US-PDT and briefly delineate the general principles of US image generation for the airway and of US-PDT procedures.
\end{abstract}

\section{Introduction}

The remarkable progress in the field of imaging has revolutionised the approach to critically ill patients. Advances in medical technology have made ultrasound (US) imaging less costly, easier to use, more precise, and sufficiently portable to be truly hand-carried. In ICUs, ultrasound scanning (USS) is frequently used to guide vascular access and procedures and for pleural and cardiac imaging. The use of USS in percutaneous dilatational tracheostomy (PDT) has the potential to improve the efficacy and reduce the complications of this common ICU procedure.

\section{Background}

PDT is commonly performed at the bedside in the ICU [1]. With an expected increase in the number of mechanically

\footnotetext{
* Correspondence: icu_mariam@yahoo.com

'Department of Critical Care Medicine, King Khalid University Hospital, College of Medicine, King Saud University, PO Box: 2925 (95), Riyadh 11461, Kingdom of Saudi Arabia

Full list of author information is available at the end of the article
}

ventilated patients, a further increase in the number of PDT procedures performed in the ICU is also expected $[2,3]$. Despite the frequency with which it is used, PDT does have limitations and risks. It is associated with higher incidences of decannulation and obstruction, particularly when it is performed by an inexperienced operator [4, 5]. Although the overall PDT complication rate is low, serious adverse events, including death, have been reported. In a national survey distributed to Head and Neck Surgery members in the American Academy of Otolaryngology via the academy's weekly email newsletter (during April and May 2011), information about catastrophic complications during and after tracheotomy was collected. Approximately 500 patients have died or been permanently disabled because of tracheotomy [6]. According to Simon and colleagues [7], a PDT-related death occurs in 1 out of every 600 patients who undergo PDT. Thirty-one percent of these deaths occur during the procedure, secondary to PDT-related haemorrhage. The second most frequent cause of death was airway complications (29.6\%). In this report, bronchoscope guidance was used in $46.5 \%$ of cases, but neither pre-nor intra-procedural PDT US was performed. In another study, most of the serious bleeding incidents were related to unrecognised and unanticipated anatomical variations in the vascular anatomy [8].

Bronchoscope guidance during PDT is used by many institutions as an additional safety adjunct $[9,10]$. It enables the confirmation of midline puncture of the trachea and allows the visualisation of posterior tracheal wall injuries, but it is not without complications [11-16]. Therefore, critical care physicians are urged to consider using other tools that could provide a better understanding of the anatomy of the neck to guide PDT procedures and improve their safety. The use of USS before, during, and after PDT could play a role in landmarking, identifying vulnerable structures, choosing the appropriate tracheostomy size, and providing real-time guidance for needle penetration. The scarce number of reports on the use of US-guided PDT 
(US-PDT) and its recent inclusion in the Australian and New Zealand Intensive Care Society practice guidelines [17] mandate a systematic review of this procedure. We performed such a review to evaluate the available literature that examined the safety and efficacy of US-PDT compared with standard techniques.

\section{Literature and evidence for the use of ultrasound guided-percutaneous dilatational tracheostomy Methods}

We performed a literature review to examine the efficacy and safety of US before or during PDT or both. MEDLINE, PubMed, EMBASE, and the Cochrane Central Register of Controlled Trials were searched for trials reporting on the safety and efficacy of US or bronchoscope guidance before and during PDT. The terms used were 'safety efficacy', 'ultrasound,' 'tracheostomy', and 'tracheotomy'.

Prospective trials that reported procedural safety or efficacy data for both the intervention group (US-PDT) and a control group of standard or bronchoscope-guided PDT cases were included. Case reports, review articles, letters to the editor, and surveys were excluded.

\section{Results}

The following sections summarise the role of USS use before, during, and after PDT.

\section{Landmarking}

The difficulties encountered in locating anatomical landmarks, such as the crico-thyroid membrane, and difficulties with tracheal puncture when the tracheal anatomy is not readily palpable are well documented [18]. Consequently, performing PDT in obese patients and patients with anatomical deformities of the neck carries a high risk of procedural complications [19]. USS of the upper airway can provide important anatomical information that would not be evident upon clinical examination alone, including information about the anatomy of the pre- and paratracheal region. USS is a safe, rapid, repeatable, portable, and widely available tool that performs well in both simulated environments and clinical practice [20-23].

\section{Choosing an appropriate tracheostomy size}

US-PDT can be used to measure the distance from the skin to the trachea, thus allowing the selection of an appropriately sized tracheostomy tube (that is, regular or extended length) [24].

\section{Identifying vulnerable structures}

Another advantage of pre-procedure USS of the neck is that it allows the identification of vulnerable structures, such as blood vessels and the thyroid gland, in the neck prior to PDT. Moreover, real-time USS performed during the procedure plays a major role in revealing potentially aberrant vessels, which allows needles and dilators to be guided away from at-risk structures, thus avoiding immediate vascular complications [8]. Several studies of fatal bleeding following PDT revealed that the addition of an ultrasonographic examination to determine the level for the PDT can help operators avoid blood vessels and visualise unanticipated anatomical variations, thereby diminishing the risk of major bleeding $[22,25,26]$.

\section{Choosing an adequate puncture location (inter-tracheal space and midline)}

The routine use of USS also enables the clear visualisation of the tracheal rings, which is necessary for the appropriate positioning of the tracheal puncture and correct midline placement [27-30]. Chacko and colleagues [31] used USS to identify the desired level of tracheal puncture on the transverse axis at the midline. This procedure was guided by pointing the needle tip toward the midline. These authors reported a median time to guide-wire insertion of 12 seconds, and the completion of the entire procedure required 12 minutes [31]. Similarly, Sustić and colleagues [32] reported that the average time required to perform US-PDT was 8 minutes, compared with 12 minutes in the surgical tracheostomy group $(P<0.05)$.

Earlier studies of models have shown that, in subjects with simulated unidentifiable anterior neck airway anatomy and tracheal deviation, the use of USS improved the speed and success of cannula placement and reduced the number of attempts required. Sustić [33] reported that the first-attempt success rate in the correct tracheal puncture site was between 96 and $100 \%$. No patients in the real-time US group suffered cranial misplacement of the tracheostomy tube, compared with $33 \%$ of the patients in the landmark group $(P<0.05)$ [34]. It is worth mentioning that an increased rate of tracheal stenosis is associated with the proximal placement of the tracheostomy tube between the cricoid cartilage and the first tracheal ring; such a placement is unlikely to occur with the use of US-PDT [35-39].

\section{Possible posterior wall tracheal injury (bronchoscope-guided versus ultrasound-guided percutaneous dilatational tracheostomy)}

Real-time US guidance makes it possible to follow the needle path during tracheal puncture and to determine the final position of the tracheostomy tube [40, 41]. However, intraluminal air prevents the visualisation of structures such as the posterior pharynx and the posterior wall of the trachea with USS; therefore, injury to the posterior wall of the trachea cannot be completely avoided [42]. 
Table 1 Summary of the best available evidence supporting the use of ultrasound-percutaneous dilatational tracheostomy

\begin{tabular}{|c|c|c|c|c|c|}
\hline Type of US guidance used & Author & Study design & Number of patients & Outcome & Complications \\
\hline \multirow[t]{2}{*}{ Pre-procedural } & Bonde et al. [39] & $\begin{array}{l}\text { Prospective Observational } \\
\text { No control group }\end{array}$ & $\begin{array}{l}28 \text { (excluded patients } \\
\text { had severe coagulopathy } \\
\text { or were morbidly obese) }\end{array}$ & $\begin{array}{l}\text { Changed puncture location in nine patients } \\
(32.1 \%) \text {; elective vessel ligation in three } \\
\text { patients (10.7\%) }\end{array}$ & $\begin{array}{l}\text { Minor bleeding in two } \\
\text { patients }(7.1 \%)\end{array}$ \\
\hline & Kollig et al. [43] & $\begin{array}{l}\text { Prospective Observational } \\
\text { No control group }\end{array}$ & 72 & $\begin{array}{l}\text { Changed puncture location in } 17 \text { patients } \\
(23.6 \%) \text {; changed to surgical tracheostomy } \\
\text { in one patient (1.3\%) }\end{array}$ & $\begin{array}{l}\text { Minor bleeding in one } \\
\text { patient }(1.3 \%)\end{array}$ \\
\hline \multirow[t]{2}{*}{ Real-time } & Sustić et al. [34] & $\begin{array}{l}\text { Retrospective Control group } \\
\text { was landmark-guided. }\end{array}$ & 26 & Cranial misplacement: $0 \%$ versus $33 \%(P<0.05)$ & $\begin{array}{l}\text { Tracheal ring fracture: } 36 \% \\
\text { versus } 43 \% \text { (not significant) }\end{array}$ \\
\hline & Rajajee et al. [46] & $\begin{array}{l}\text { Prospective Feasibility } \\
\text { No control group }\end{array}$ & 13 & $\begin{array}{l}\text { All PDTs were successful. Appropriate positioning } \\
\text { of puncture was confirmed on bronchoscopy. }\end{array}$ & $\begin{array}{l}\text { No significant complications } \\
\text { were reported. }\end{array}$ \\
\hline Pre-procedural US and real-time & Guinot et al. [24] & $\begin{array}{l}\text { Prospective Observational } \\
\text { No control group }\end{array}$ & $\begin{array}{l}50 \text { (obese patients and } \\
\text { patients with severe } \\
\text { coagulopathy were } \\
\text { excluded) }\end{array}$ & $\begin{array}{l}\text { All PDTs were successful. Puncture location } \\
\text { was changed in } 25 \text { patients (50\%). }\end{array}$ & $\begin{array}{l}\text { Minor bleeding in three patients } \\
(6 \%) \text {; wound infection in one } \\
\text { patient ( } 2 \%)\end{array}$ \\
\hline Real-time US guidance & Rudas et al. [47] & Randomised controlled trial & 50 & $\begin{array}{l}\text { First-pass success rates were } 87 \% \text { in the US } \\
\text { group and } 58 \% \text { in the landmark group }(P=0.028) \text {. }\end{array}$ & $\begin{array}{l}\text { The decrease in procedural } \\
\text { complications was not } \\
\text { statistically significant: } 22 \% \\
\text { in the US group versus } 37 \% \\
\text { in the landmark group }(P=0.24 \text { ). }\end{array}$ \\
\hline Pre- and post-procedural US & Yavuz et al. [48] & Randomised controlled trial & 341 & $\begin{array}{l}\text { The puncture sites designated at the physical } \\
\text { examination were reconsidered in } 23.8 \% \text { of } \\
164 \text { cases. The mean procedure times for } \\
\text { the US group and the controls were } \\
24.09 \text { minutes } \pm 8.05 \text { and } 18.62 \\
\text { minutes } \pm 6.34 \text {, respectively }(P=.001) \text {. }\end{array}$ & $\begin{array}{l}\text { The perioperative complication } \\
\text { rates were slightly lower in the } \\
\text { US group }(7.8 \%) \text { than in the } \\
\text { control group }(15.0 \%) \text {; not } \\
\text { statistically significant }(P=0.054) \text {. }\end{array}$ \\
\hline
\end{tabular}

All studies were performed in intensive care units. PDT, percutaneous dilatational tracheostomy; US, ultrasound 


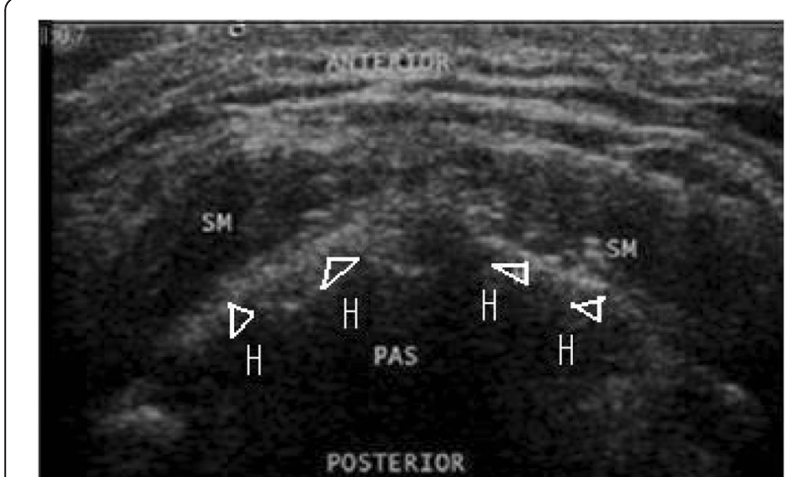

Midline transverse view at hyoid

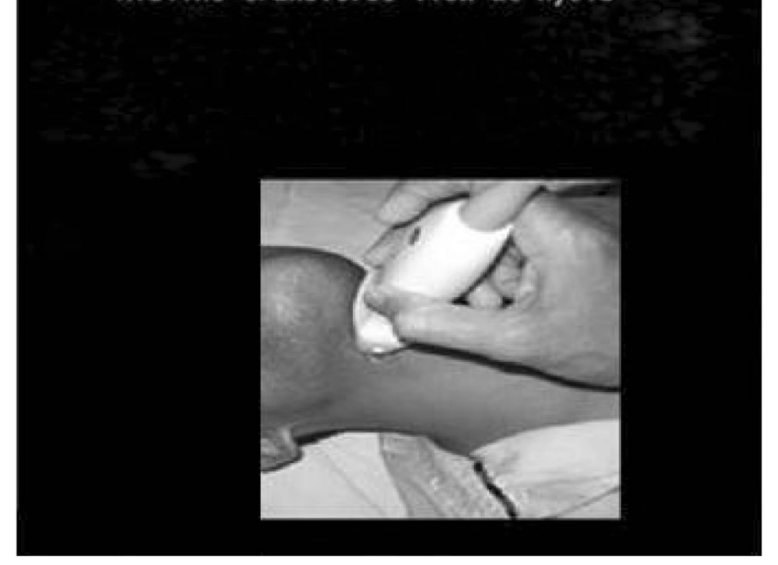

Fig. 1 Sonogram of the hyoid bone $(H)$ on a midline transverse view using a linear transducer. The hyoid bone is shown as an inverted, hyper-echoic U. PAS, posterior acoustic shadow; SM, strap muscles. Reprinted with permission from Wolters Kluwer [42]

Kollig and colleagues [43] reported on 72 consecutive patients requiring PDT who underwent pre-procedure USS evaluation of the neck to assess the level of tracheal puncture, followed by bronchoscope-guided PDT to identify posterior wall injury. Bronchoscope use during the tracheal puncture carries safety risks resulting from the possibility of inaccurate device placement and associated temporary hypoventilation. Moreover, accidental needle puncture of the bronchoscope is a common problem that can lead to high repair costs. The disadvantages of not using a bronchoscope include diminished control of the airway, an inability to detect posterior wall injury and ring fractures, a decreased ability to perform pulmonary toilet around the procedure site, and a diminished ability to detect false passage of the tube, particularly if the guide wire is accidentally pulled back too far.

No studies have yet compared bronchoscope-guided PDT alone with US-guided PDT. Such a comparison is mandatory if we are to improve the PDT technique, minimise patient risks, and eliminate financial burdens.

\section{Detecting pneumothorax}

The use of portable US to detect pneumothorax has long been studied [44]. Recently, an evidence-based review of the literature compared the abilities of ultrasonography with chest radiography to detect pneumothorax. Bedside ultrasonography was a much more sensitive screening test for pneumothorax compared with supine chest radiography (the time to diagnose pneumothorax was 7 minutes for ultrasonography versus 80 minutes in the $\mathrm{x}$-ray group) [45]. Ultrasonography is an obvious first choice for the post-PDT diagnosis of pneumothorax. However, no studies have yet reported on the detection of post-PDT pneumothorax using ultrasonography.

Only a few prospective randomised controlled trials (RCTs) have compared the safety and efficacy of US-PDT with the traditional landmark-guided technique (with or without bronchoscopy). The remainder of the available studies are all small and largely observational in nature. Table 1 [24, 34, 39, 43, 46-48] summarises the best available evidence to date. Most studies have reported low periprocedural complication rates, but no control groups were used for comparison. It should be noted that the incidence of significant complications following PDT is low; therefore, a large sample size would be required to detect a beneficial effect. No studies have reported long-term follow-up.

Because of the lack of strong supporting evidence, US-PDT is not yet practiced routinely. The small number of available studies suggests that US-PDT is safe and offers a potential benefit over the traditional landmark-guided procedure, particularly in selected patient groups, such as obese patients. Therefore, we decided to describe the procedure in detail (supported by images) to encourage critical care physicians to consider the great safety potential associated with the use of US-PDT and to plan for conducting a large RCT comparing US-PDT with bronchoscope-guided PDT.

\section{Ultrasound use in percutaneous dilatational tracheostomy}

The basic principle of ultrasound imaging of the airways

Transducer selection is important when evaluating the anatomy of the airway. Higher-frequency linear probes (7.5 MHz) provide better resolution of superficial structures. Therefore, they are the most suitable type of probe for imaging superficial airway structures (within 2 to $3 \mathrm{~cm}$ from the skin). In contrast, the curved low-frequency $(5 \mathrm{MHz})$ transducer is best used for obtaining sagittal and parasagittal views of structures in the submandibular and supraglottic regions [49]. These probes produce twodimensional grayscale images on the screen, ranging from black to white [50].

Hyperechoic structures (such as fat and bone) give a strong echo and thus appear white [51]. Fluid collections 
A

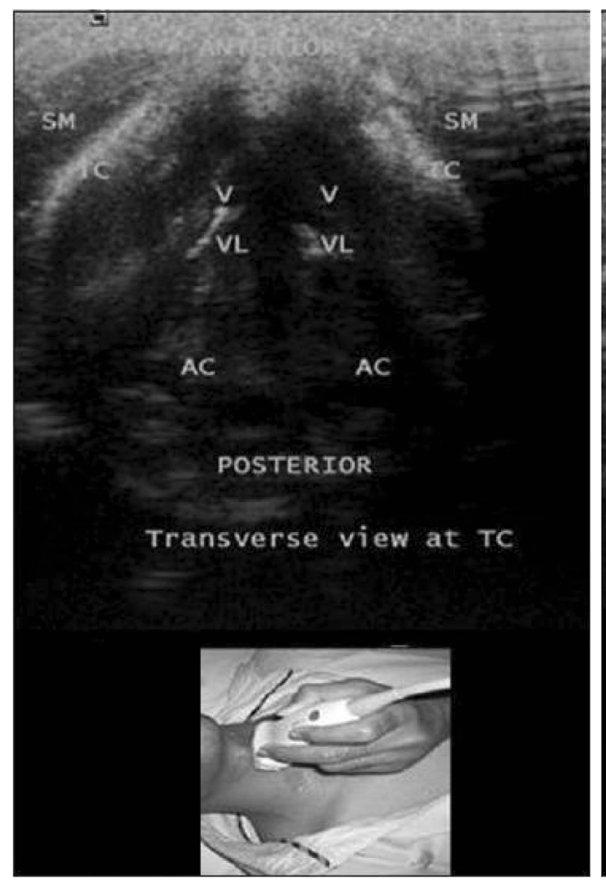

B

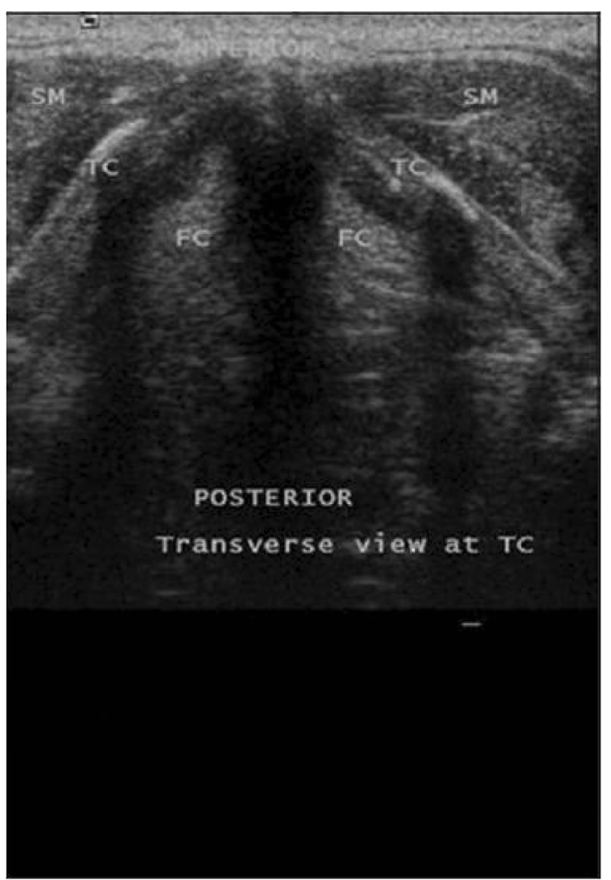

Fig. 2 Transverse view at the thyroid cartilage using a linear transducer. Note the difference in echogenicity between the true cords because of the presence of the vocalis muscle (A) (TC, Thyroid cartilage; SM, Strap muscles; AC, Arytenoid cartilage; V, Vocalis muscle; VL, Vocal ligaments;) and the increased fat content in the false cords (B) (TC, Thyroid cartilage; SM, Strap muscles; FC, False cord;). Reprinted with permission from Wolters Kluwer [42]

or blood vessels let the US beam pass through them easily, creating little echo. They are called anechoic structures, and they appear black on the screen. Cartilaginous structures (such as the thyroid cartilage, the cricoid cartilage, and the tracheal rings) appear as homogeneous, hypoechoic (black) structures. Muscles and connective tissue membranes are also hypoechoic, but they have a more heterogeneous, striated appearance than cartilage does [52]. Air conducts US very weakly, so when the US beam reaches the tissue/air border, a strong reflection (a strong white line) appears, and everything on the screen beyond that point consists of artefacts. Because men have a prominent thyroid cartilage, it is sometimes a challenge to avoid air under the probe when performing a sagittal midline scan from the hyoid bone to the suprasternal notch. This difficulty can be overcome by applying a liberal amount of conductive gel or another fluid-filled interface (for example, a water bath) between the probe and the skin $[31,50]$.

\section{The ultrasound-guided percutaneous dilatational tracheostomy procedure and tips}

Before proceeding to the PDT, the pre-tracheal area should be examined for the tracheal midline, the tracheal cartilage level, the anterior jugular veins (their diameter and location relative to the midline), and the thyroid isthmus or midline vessel. Aberrant vascular structures crossing the midline can also be observed and should be noted. In evaluating vascular structures, it is important to ensure that the structures are not compressed by excessive pressure from the probe. If in doubt, further evaluation using colour Doppler can be performed [30]. Such preprocedural USS is likely to lead to a change in the planned location of the tracheal puncture in up to $50 \%$ of cases, mostly to avoid puncturing the thyroid isthmus or an aberrant vessel $[43,53]$.

Ideally, the space between the first and second or the second and third tracheal rings should be selected for the insertion of the tracheostomy tube. According to sonographic criteria, the point of tracheal puncture should be below the first tracheal ring but above the fifth tracheal ring, with no vascular structures in the path of the needle. The precise inter-tracheal ring space is considered less important than the passage below the first and above the fifth tracheal rings [54].

Avoiding the thyroid isthmus is often not possible and is not believed to be necessary [55]. However, rare but fatal complications, such as arterial bleeding from a thyroid artery or from an avulsed subclavian artery, have been reported during or after tracheostomy. It is also best to avoid making the tracheal access below the third tracheal ring, where the thyroid isthmus is 
likely to lie $[56,57]$. The goal is to puncture the anterior quadrant of the trachea, placing the puncture sites between the 11 and 1 o'clock positions as close as possible to the midline [58].

In morbidly obese patients or patients with anatomical deformities resulting from pathology or injuries, palpation is almost always difficult or even impossible [18, 19, 59]. Therefore, USS should be used in conjunction with palpation of the neck prior to commencing the procedure.

For morbidly obese patients, US should first be used with the head in the neutral position to estimate the thickness of the soft tissue between the skin and the trachea to determine the length of the tracheostomy tube. The mode of imaging should then be adjusted while the trachea is in the centre of the screen to maximise the resolution and depth of imaging.

After induction and positioning, the endotracheal tube should be withdrawn under direct laryngoscopic visualisation until the cuff is positioned immediately inferior to the vocal cords using a standard laryngoscope. Some operators have pulled the endotracheal tube back under US guidance until the cuff is at the level of the thyroid cartilage [60].

With a linear array probe in a sterile sheath, it is possible to obtain transverse/axial real-time images of the upper airway, starting from the hyoid bone down to the thyroid gland and its isthmus. The viewed airway should always be in the centre of the screen. On axial imaging, the airway in the neck should be apparent at the midline and should show mixed hyper-echogenicity. The hyoid bone is a key landmark that separates the upper airway into the suprahyoid and infrahyoid regions (Fig. 1). The inverted V-shaped thyroid cartilage, within which the vocal cords lie, should then be identified caudal to the hyoid bone (Fig. 2).

By sliding the probe caudally, the clinician can identify the cricoid cartilage within the anterior wall of the larynx caudal to the cricothyroid membrane by its relatively large acoustic shadow (seen as a hump on the transverse view; Fig. 3). The posterior surface of its anterior wall is delineated by a bright air-mucosal (A-M) interface and by reverberation artefacts from intraluminal air (Fig. 3). Caudal to the cricoid cartilage, the tracheal rings will be observed. They can be identified by their relatively thin acoustic shadows within the anterior wall of the trachea. Like all cartilaginous structures, the tracheal rings appear hypoechoic. They resemble an inverted $U$, highlighted by a linear hyperechoic A-M interface and by reverberation artefacts posteriorly (Fig. 4). On sagittal views, they resemble a string of beads. The thyroid gland (with a speckled, homogeneous, hyperechoic appearance) and the isthmus should then be delineated at the level of the suprasternal notch (Fig. 5).

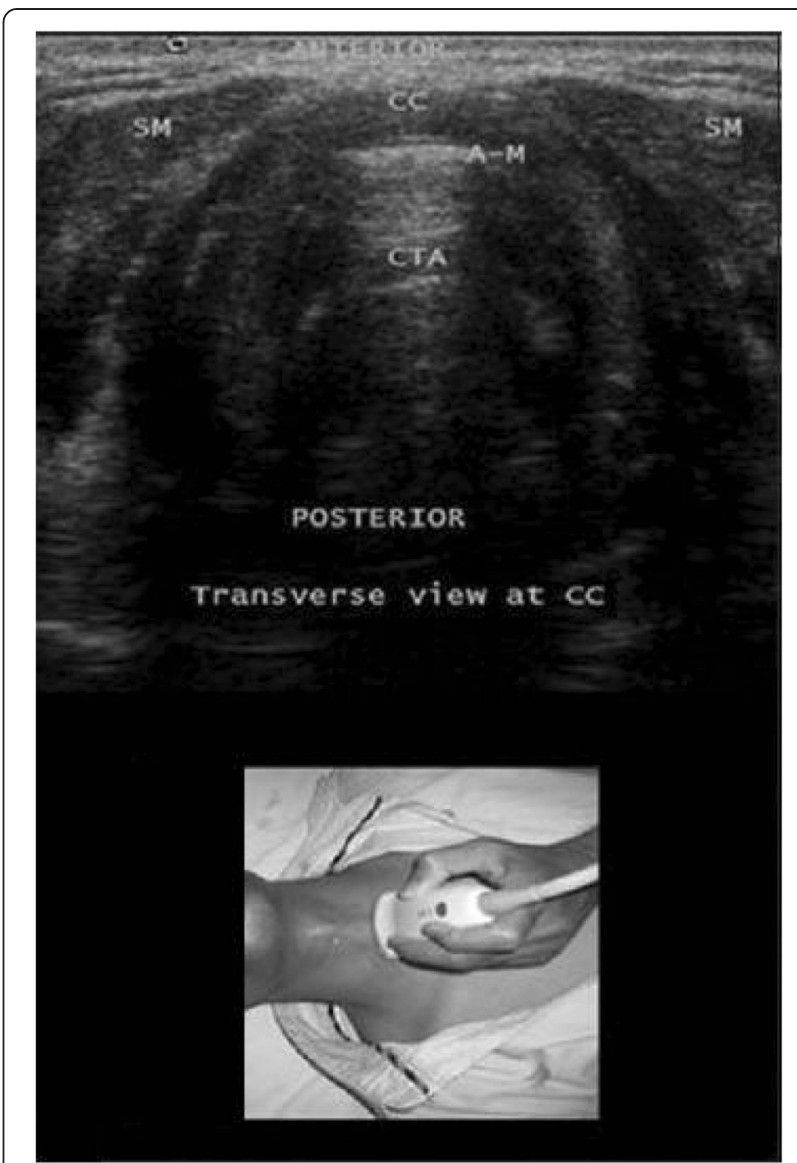

Fig. 3 Transverse view at the cricoid cartilage. A-M, air mucosal interface; CC, cricoid cartilage; CTA, comet tail artefacts; SM, strap muscles. Reprinted with permission from Wolters Kluwer [42]

Transverse/axial real-time imaging of the trachea allows continuous visualisation of the tracheal midline. Deviation of the guide wire too far from the midline can occur and can cause paratracheal tissue damage during the subsequent dilatation. Placing the transducer transverse to the tracheal cartilage and first obtaining a short-axis US image allow the identification of the tracheal midline, thereby helping to avoid this problem. However, on this view, it can be difficult to identify the correct space between the tracheal rings and to differentiate cartilage from air. We therefore recommend obtaining the details of the midline of the neck on the transverse/axial view, determining the absence of aberrant structures, and then moving the probe 90 degrees to obtain a longitudinal view with the cricoid cartilage and the first tracheal ring in the centre of the US screen. On this view, the space between the first and second or second and third tracheal cartilage at the midline of the trachea can be identified (Fig. 4). This approach allows the needle, a 15-G thin-wall needle, to be followed as it is advanced while the laryngeal cartilage and the tracheal cartilage are visible and can be easily differentiated from the air between the cartilages. As the needle 


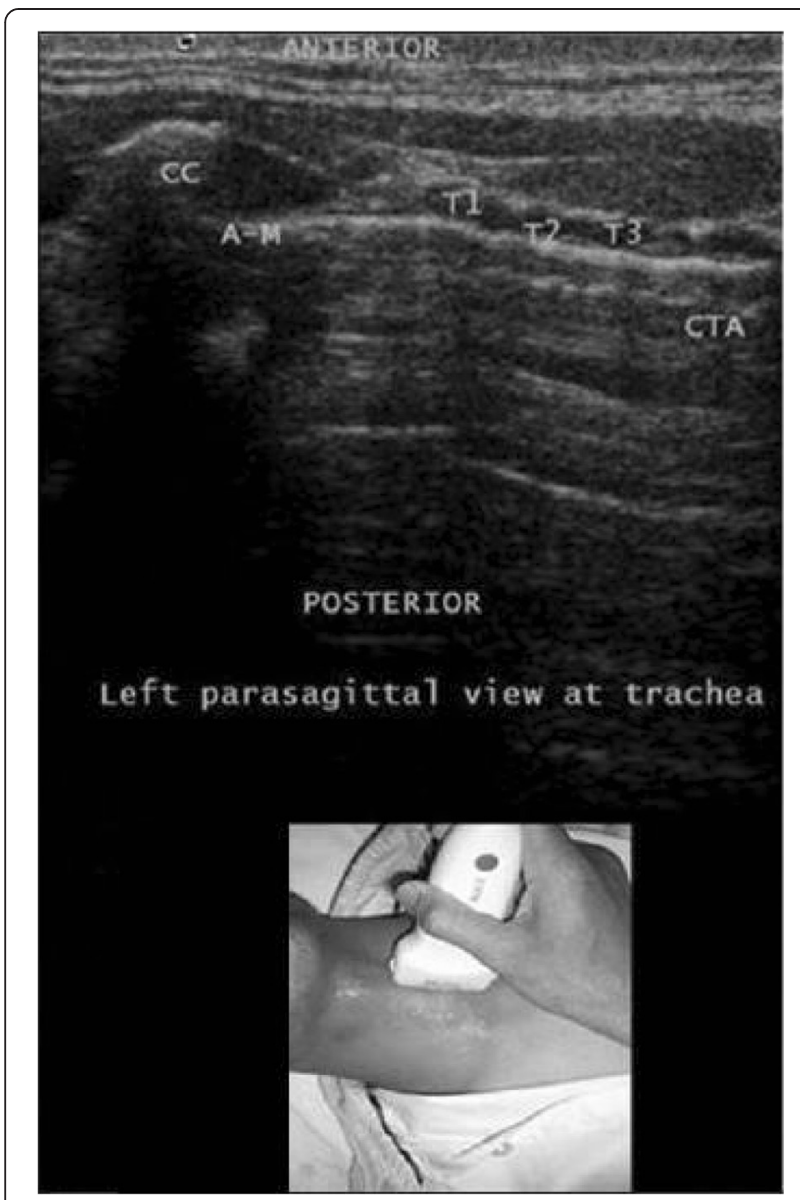

Fig. 4 Left parasagittal view at the trachea. A-M, air-mucosal interface; CC, cricoid cartilage; CTA, comet tail artefact; $T 1-T 3$, tracheal cartilage. Reprinted with permission from Wolters Kluwer [42] passes through the anterior wall, a change in resistance is felt and the lumen is entered, followed by the aspiration of air/fluid into the attached syringe.

This so-called in-plane approach can sometimes be difficult in patients with short necks because of a lack of physical space. In such cases, a perpendicular angle of puncture is preferred, despite the increased risk of injury to the posterior wall of the trachea. In this approach, the transverse probe is positioned immediately above the level of the planned puncture. With slight caudal angulation of the probe, good visualisation and direction of the needle tip toward the tracheal midline should be possible. The needle is introduced perpendicularly to the skin, and the path is determined by the distinct acoustic shadow ahead of the needle, followed by the displacement of tissue layers observed with needle passage. The indentation of the anterior tracheal wall by the needle can sometimes be observed on these US images. This technique has been described by Chacko and colleagues [31].

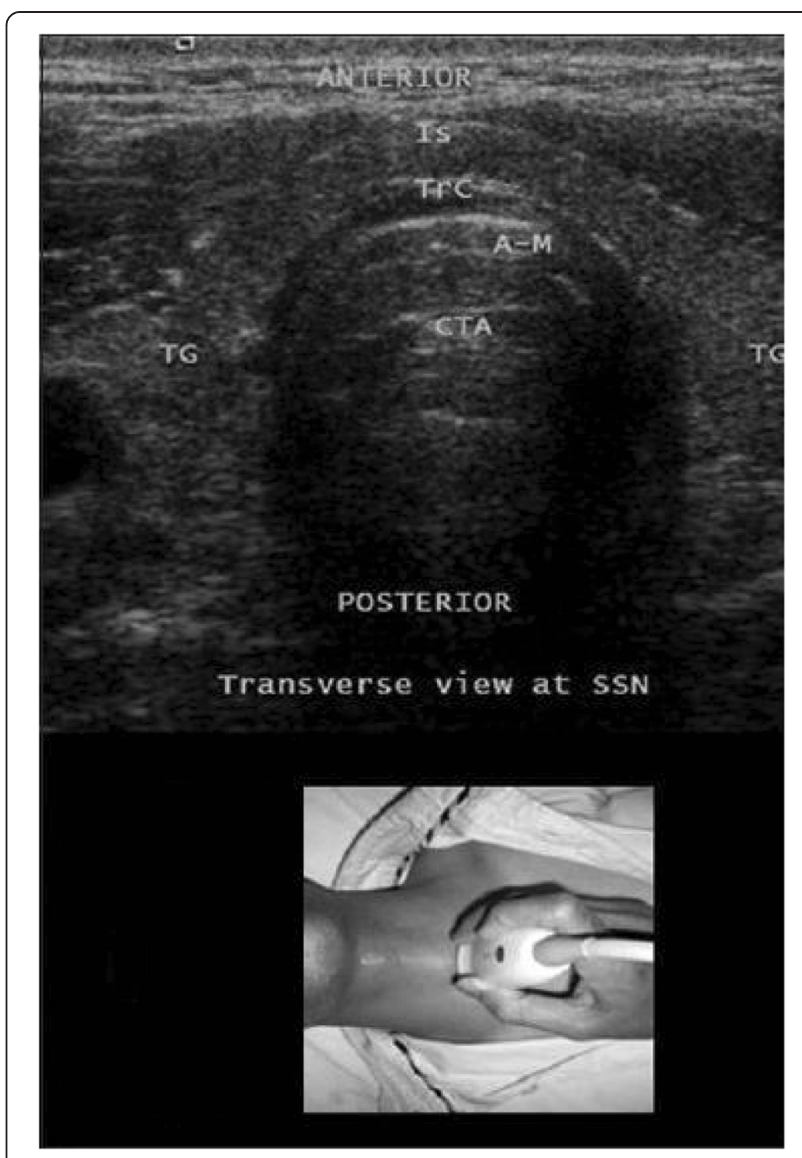

Fig. 5 Transverse view at the level of the suprasternal notch (SSN) showing the trachea and the thyroid gland. A-M, air-mucosal interface; CTA, comet tail artefact; Is, isthmus; TG, thyroid gland; Trc, tracheal cartilage (ring). Reprinted with permission from Wolters Kluwer [42]

As soon as a loss of resistance is felt or air or fluid is aspirated into the attached syringe, the US probe is set aside, and the syringe is disconnected. A guide wire from a pre-assembled tracheostomy kit is then inserted through the needle into the trachea as a guide for further tracheostomy. Finally, a bronchoscope is used to determine whether injury to the posterior wall of the trachea has occurred.

\section{Conclusions}

As US technology continues to evolve, its scope is becoming limited only by operator expertise and not by the capabilities of the bedside unit. USS of the upper airway can provide a great deal of anatomical information that would not be evident with clinical examination alone. With the development of better probes, high-resolution imaging, real-time pictures, and clinical experience, USS has become a potential first-line noninvasive airway assessment tool in intensive care practice. However, until prospective RCTs are 
conducted to evaluate the safety and efficacy of US-PDT compared with the traditional landmark-guided technique, the best available evidence highly recommends the use of USS prior to, during, and after PDT to improve the safety of the procedure.

\section{Abbreviations}

A-M: Air-mucosal; PDT: Percutaneous dilatational tracheostomy; RCT: Randomised controlled trial; US: Ultrasound; US-PDT: Ultrasound-guided percutaneous dilatational tracheostomy; USS: Ultrasound scanning.

\section{Competing interests}

The authors declare that they have no competing interests. The subject of this review has no connections with any company or financial sponsor.

\section{Authors' contributions}

MA conceived of the idea and participated in the literature review, the drafting of the manuscript, and the revision for important intellectual content. HA participated in the literature review and the drafting of the manuscript. ZA participated in the literature review and added a small section and then contributed to the final revision, including the English editing. MAE helped to collect images and participated in the literature review and the drafting of the manuscript. All authors read and approved the final manuscript.

\section{Acknowledgements}

The work was supported by the College of Medicine Research Centre and the Deanship of Scientific Research, King Saud University Riyadh, Saudi Arabia. The images were reproduced with the permission of the Indian Journal of Anaesthesia.

\section{Author details}

'Department of Critical Care Medicine, King Khalid University Hospital, College of Medicine, King Saud University, PO Box: 2925 (95), Riyadh 11461, Kingdom of Saudi Arabia. ${ }^{2}$ Department of Emergency Medicine, King Khalid University Hospital, College of Medicine, King Saud University, PO Box: 2925 (95), Riyadh 11461, Kingdom of Saudi Arabia.

\section{Published online: 18 May 2015}

\section{References}

1. Delaney A, Bagshaw SM, Nalos M. Percutaneous dilatational tracheostomy versus surgical tracheostomy in critically ill patients: a systematic review and meta-analysis. Crit Care. 2006;10:R55

2. Needham DM, Bronskill SE, Calinawan JR, Sibbald WJ, Pronovost PJ, Laupacis A. Projected incidence of mechanical ventilation in Ontario to 2026: preparing for the aging baby boomers. Crit Care Med. 2005;33:574-9.

3. Zilberberg MD, de Wit M, Pirone JR, Shorr AF. Growth in adult prolonged acute mechanical ventilation: implications for healthcare delivery. Crit Care Med. 2008;36:1451-5.

4. Higgins KM, Punthakee X. Meta-analysis comparison of open versus percutaneous tracheostomy. Laryngoscope. 2007;117:447-54.

5. Massick DD, Yao S, Powell DM, Griesen D, Hobgood T, Allen JN, et al. Bedside tracheostomy in the intensive care unit: a prospective randomized trial comparing open surgical tracheostomy with endoscopically guided percutaneous dilational tracheotomy. Laryngoscope. 2001;111:494-500.

6. Das P, Zhu H, Shah RK, Roberson DW, Berry J, Skinner ML. Tracheotomy related catastrophic events: results of a national survey. Laryngoscope. 2012;122:30-7

7. Simon M, Metschke M, Braune SA, Püschel K, Kluge S. Death after percutaneous dilatational tracheostomy: a systematic review and analysis of risk factors. Crit Care. 2013;17:R258.

8. McCormick B, Manara AR. Mortality from percutaneous dilatational tracheostomy. A report of three cases. Anaesthesia. 2005;60:490-5.

9. Sarkar S, Kelly A, Townsend R. Survey of percutaneous tracheostomy practice in UK intensive care units. JICS. 2009:10:138-40.

10. Kluge S, Baumann HJ, Maier C, Klose H, Meyer A, Nierhaus A, et al. Tracheostomy in the intensive care unit: a nationwide survey. Anesth Analg. 2008;107:1639-43.
11. Trottier SJ, Hazard PB, Sakabu SA, Levine JH, Troop BR, Thompson JA, et al. Posterior tracheal wall perforation during percutaneous dilatational tracheostomy: an investigation into its mechanism and prevention. Chest. 1999;115:1383-9.

12. Reilly PM, Shapiro MB, Malcynski JT. Percutaneous dilatational tracheostomy under the microscope: justification for intra-procedural bronchoscopy? Intensive Care Med. 1999;25:3-4.

13. Reilly PM, Anderson III HL, Sing RF, Schwab W, Bartlett RH. Occult hypercarbia: an unrecognized phenomenon during percutaneous endoscopic tracheostomy. Chest. 1995;107:760-3.

14. Reilly PM, Sing RF, Giberson FA, Anderson III HL, Rotondo MF, Tinkoff GH, et al. Hypercarbia during tracheostomy: a comparison of percutaneous endoscopic, percutaneous Doppler, and standard surgical tracheostomy. Intensive Care Med. 1997;23:858-64.

15. Paran H, Butnaru G, Hass I, Afanasyv A, Gutman M. Evaluation of a modified percutaneous tracheostomy technique without bronchoscopic guidance. Chest. 2004;126:868-71.

16. Elliott DS, Baker PA, Scott MR, Birch CW, Thompson JM. Accuracy of surface landmark identification for cannula cricothyroidotomy. Anaesthesia. 2010;65:889-94.

17. Australian New Zealand Intensive Care Society (ANZICS). Percutaneous Dilatational Tracheostomy - Consensus Statement. Carlton, South Victoria: Australian New Zealand Intensive Care Society; 2014. http://www.anzics. com.au/Downloads/2014\%20The\%20ANZICS\%20Percutaneous\% 20Dilatational\%20Tracheostomy\%20Consensus\%20Statement.pdf.

18. Husein OF, Massick DD. Cricoid palpability as a selection criterion for bedside tracheostomy. Otolaryngol Head Neck Surg. 2005;133:839-44.

19. Byhahn C, Lischke V, Meininger D, Halbig S, Westphal K. Perioperative complications during percutaneous tracheostomy in obese patients. Anaesthesia. 2005;60:12.

20. Pearson N, Huebner K. The use of ultrasound guidance for cricothyroidotomy in three simulated cadaveric difficult airway models. Ann Emerg Med. 2012;3:159.

21. Dinsmore J, Heard AM, Green RJ. The use of ultrasound to guide time-critical cannula tracheotomy when anterior neck airway anatomy is unidentifiable. Eur J Anaesthesiol. 2011;28:506-10.

22. Sustić A, Zupan Z, Antoncić I. Ultrasound-guided percutaneous dilatational tracheostomy with laryngeal mask airway control in a morbidly obese patient. J Clin Anesth. 2004;16:121-3.

23. Baumber R. Neck ultrasound prior to percutaneous tracheostomy: should this now be a standard of practice? J Intens Care Soc. 2011;12:342.

24. Guinot PG, Zogheib E, Petiot S, Marienne JP, Guerin AM, Monet P, et al. Ultrasound-guided percutaneous tracheostomy in critically ill obese patients. Crit Care. 2012;16:R40.

25. Shlugman D. Acute fatal haemorrhage during percutaneous dilatational tracheostomy. Br J Anaesth. 2003;90:517-20.

26. Sustić A, Zupan Z, Eskinja N, Dirlić A, Bajek G. Ultrasonographically guided percutaneous dilatational tracheostomy after anterior cervical spine fixation. Acta Anaesthesiol Scand. 1999;43:1078-80.

27. Bertram S, Emshoff R, Norer B. Ultrasonographic anatomy of the anterior neck: implications for tracheostomy. J Oral Maxillofacial Surg. 1995;53:1420-4.

28. Tremblay LN, Scales DC. Ultrasound-guided tracheostomy - not for the many, but perhaps the few... or the one. Crit Care. 2011;15:147.

29. Hatfield A, Bodenham A. Portable ultrasonic scanning of the anterior neck before percutaneous dilatational tracheostomy. Anaesthesia. 1999:54:660-3.

30. Flint AC, Midde R, Rao VA, Lasman TE, Ho PT. Bedside ultrasound screening for pretracheal vascular structures may minimize the risks of percutaneous dilatational tracheostomy. Neurocrit Care. 2009;11:372-6.

31. Chacko J, Nikahat J, Gagan B, Umesh K, Ramanathan M. Realtime ultrasound-guided percutaneous dilatational tracheostomy. Intensive Care Med. 2012;38:920-1.

32. Sustić A, Krstulovic B, Eskinja N, Zelic M, Ledic D, Turina D. Surgical tracheostomy versus percutaneous dilational tracheostomy in patients with anterior cervical spine fixation: preliminary report. Spine (Phila Pa 1976). 2002;27:1942-5.

33. Sustic $A$. Role of ultrasound in the airway management of critically ill patients. Crit Care Med. 2007;35:137-77.

34. Sustić A, Kovac D, Zgaljardić Z, Zupan Z, Krstulović B. Ultrasound-guided percutaneous dilatational tracheostomy: a safe method to avoid cranial misplacement of the tracheostomy tube. Intensive Care Med. 2000;26:1379-81.

35. MCFarlane C, Denholm SW, Sudlow CL, Moralee SJ, Grant IS, Lee A. Laryngotracheal stenosis: a serious complication of percutaneous tracheostomy. Anaesthesia. 1994;49:38-40. 
36. Van Heurn LW, Theunissen PH, Ramsay G, Brink PR. Pathologic changes of the trachea after percutaneous dilatational tracheostomy. Chest. 1996;109:1466-9.

37. Walz MK, Schmidt U. Tracheal lesion caused by percutaneous dilatational tracheostomy - a clinico-pathological study. Intensive Care Med. 1999;25:102-5.

38. Sarper A, Ayten A, Eser I, Ozbudak O, Demircan A. Tracheal stenosis after tracheostomy or intubation: review with special regard to cause and management. Texas Heart Institute J. 2005;32:154-8.

39. Bonde J, Nørgaard N, Antonsen K, Faber T. Implementation of percutaneous dilation tracheotomy - value of preincisional ultrasonic examination? Acta Anaesthesiol Scand. 1999;43:163-6.

40. Szeto C, Kost K, Hanley JA, Roy A, Christou N. A simple method to predict pretracheal tissue thickness to prevent accidental decannulation in the obese. Otolaryngol Head Neck Surg. 2010;143:223-9.

41. Ambesh SP. Principles and Practice of Percutaneous Tracheostomy. Croatia: Jaypee Brothers Medical Publisher; 2010.

42. Kundra P, Mishra SK, Ramesh A. Ultrasound of the airway. Indian J Anaesth. 2011;55:456-62.

43. Kollig E, Heydenreich U, Roetman B, Hopf F, Muhr G. Ultrasound and bronchoscopic controlled percutaneous tracheostomy on trauma ICU. Injury. 2000;31:663-8

44. Lichtenstein DA, Mezière G, Lascols N, Biderman P, Courret JP, Gepner A, et al Ultrasound diagnosis of occult pneumothorax. Crit Care Med. 2005;33:1231-8.

45. Kaya SO, Karatepe M, Tok T, Onem G, Dursunoglu N, Goksin I. Were pneumothorax and its management known in 15th-century anatolia? Tex Heart Inst J. 2009;36:152-3.

46. Rajajee $V$, Fletcher JJ, Rochlen LR, Jacobs TL. Real-time ultrasound-guided percutaneous dilatational tracheostomy: a feasibility study. Crit Care. 2011;15:R67.

47. Rudas M, Seppelt I, Herkes R, Hislop R, Rajbhandari D, Weisbrodt L. Traditional landmark versus ultrasound guided tracheal puncture during percutaneous dilatational tracheostomy in adult intensive care patients: a randomised controlled trial. Crit Care. 2014;18:514.

48. Yavuz A, Yılmaz M, Göya C, Alimoglu E, Kabaalioglu A. Advantages of US in percutaneous dilatational tracheostomy: randomized controlled trial and review of the literature. Radiology. 2014;273:927-36.

49. Hangiandreou N. AAPM/RSNA physics tutorial for residents: topics in US. B-mode US: basic concepts and new technology. Radiographics. 2003;23:1019-33.

50. Noble VE, Nelson B, Sutingco AN. Manual of Emergency and Critical Care Ultrasound. New York: Cambridge University Press; 2007.

51. Singh M, Chin KJ, Chan WW, Wong DT, Prasad GA, Yu E. Use of sonography for airway assessment: an observational study. J Ultrasound Med. 2010;29:79-85.

52. Sites BD, Brull R, Chan WW, Spence BC, Gallagher J, Beach ML, et al. Artifacts and pitfall errors associated with ultrasound-guided regional anesthesia. Part II: a pictorial approach to understanding and avoidance. Reg Anesth Pain Med. 2007;32:419-33.

53. Kossoff G. Basic physics and imaging characteristics of ultrasound. World J Surg. 2000;24:134-42.

54. Rudas $M$. The role of ultrasound in percutaneous dilatational tracheostomy. AJUM. 2012;15:143-8.

55. Praveen CV, Martin A. A rare case of fatal haemorrhage after tracheostomy. Ann R Coll Surg Engl. 2007;89:W6-8.

56. Della Puppa A, Pittoni G. Inferior thyroid artery bleeding: a life-threatening complication of non-surgical tracheostomy. Minerva Anestesiol. 2001;67:483-5.

57. Kleine-Brueggeney M, Greif R, Ross S, Eichenberger U, Moriggl B, Arnold A, et al. Ultrasound-guided percutaneous tracheal puncture: a computer-tomographic controlled study in cadavers. Br J Anaesthesia. 2011;106:738-42.

58. Kost KM. Endoscopic percutaneous dilatational tracheotomy: a prospective evaluation of 500 consecutive cases. Laryngoscope. 2005;115:1-30.

59. Rezende-Neto JB, Oliveira AJ, Neto MP, Botoni FA, Rizoli SB. A technical modification for percutaneous tracheostomy: prospective case series study on one hundred patients. World J Emerg Surg. 2011;6:35.

60. Dunne K, Ball D, Jefferson P. Cannula cricothyroidotomy: management of false-negative aspiration. Anaesthesia. 2009;64:1375. 